\title{
Contributions of childhood peer victimization and/or maltreatment to young adult anxiety, depression, and suicidality: a cross-sectional study
}

\author{
Melissa Macalli $i^{1^{*}}$, Massimiliano Orri ${ }^{1,2}$, Christophe Tzourio ${ }^{1,3^{*}+}$ and Sylvana M. Côté ${ }^{1,4 \dagger}$
}

\begin{abstract}
Background: Childhood maltreatment and peer victimization are major risk factors for depression and suicidal behavior. Furthermore, childhood maltreatment increases the risk of peer victimization. Our objective was to distinguish between the contributions of parental maltreatment and peer victimization to the development of mental health problems in young adulthood. Specifically, we tested whether peer victimization alone or in combination with parental maltreatment before 18 years old was associated with anxiety, depression, and suicidal thoughts and behaviors at age 21 years.

Methods: We analyzed data collected from questionnaires administered in the i-Share (Internet-based Students' Health ResearchEnterprise) study in France from February 2013 to September 2019 ( $N=2271$ participants). We performed multinomial and binary logistic regression analyses to assess the single and combined contributions of childhood peer victimization and parental maltreatment to anxiety, depression, and suicidality in adulthood.

Results: Nearly one third of students (28.8\%) reported at least one mental health problem; 29.8\% reported peer victimization alone; $7.5 \%$ reported parental maltreatment alone; and $10.3 \%$ reported both parental maltreatment and victimization. In multivariate models, compared to participants that did not experience maltreatment or peer victimization, those that experienced peer victimization alone were more likely to report anxiety (adjusted odds ratio [aOR]: 1.90; 95\% Cl: 1.50-2.40), depression (aOR: 1.95; 95\% Cl: 1.46-2.60), or suicidal ideation, without (aOR: 1.62; 95\% Cl: 1.26-2.09) or with a suicide attempt (aOR: 2.70; 95\% Cl: 1.51-4.85). Similar associations were observed for participants that experienced maltreatment alone. Participants that experienced both maltreatment and peer victimization were at increased risk of depression (aOR: 2.63; 95\% Cl: 1.79-3.86) and suicidal ideation, with (aOR: 9.19; 95\% Cl: 4.98-16.92) and without a suicide attempt (aOR: 2.64; 95\% Cl: 1.86-3.76).
\end{abstract}

\footnotetext{
*Correspondence: melissa.macalli@u-bordeaux.fr; christophe.tzourio@u-

bordeaux.fr

${ }^{\dagger}$ Christophe Tzourio and Sylvana M. Côté share last authorship.

${ }^{1}$ University of Bordeaux, Inserm, Bordeaux Population Health Research Center, UMR 1219, F-33000 Bordeaux, France

Full list of author information is available at the end of the article
}

C C The Author(s). 2021 Open Access This article is licensed under a Creative Commons Attribution 4.0 International License, which permits use, sharing, adaptation, distribution and reproduction in any medium or format, as long as you give appropriate credit to the original author(s) and the source, provide a link to the Creative Commons licence, and indicate if changes were made. The images or other third party material in this article are included in the article's Creative Commons licence, unless indicated otherwise in a credit line to the material. If material is not included in the article's Creative Commons licence and your intended use is not permitted by statutory regulation or exceeds the permitted use, you will need to obtain permission directly from the copyright holder. To view a copy of this licence, visit http://creativecommons.org/licenses/by/4.0/ The Creative Commons Public Domain Dedication waiver (http://creativecommons.org/publicdomain/zero/1.0/) applies to the data made available in this article, unless otherwise stated in a credit line to the data. 
Conclusions: Separate and combined exposures to parental maltreatment and peer victimization in childhood or adolescence were associated with increased risks of anxiety, depression, and suicidal behaviors. Peer victimization appeared to play a specific role in mental health disorders that were not otherwise explained by polyvictimization. Currently, peer victimization is a frequent, but avoidable type of child abuse; therefore, these findings have implications for policies for preventing and dealing with peer victimization.

Keywords: Peer victimization, Childhood maltreatment, Mental health, Anxiety, Depression, Suicidality, Young adults

\section{Background}

Maltreatment and peer victimization in childhood are recognized as important risk factors for mental health problems worldwide $[1,2]$, including anxiety, depression, and suicidal behavior [3-8]. Child maltreatment includes all types of physical and/or emotional ill-treatment, sexual abuse, neglect, or negligence, which may result in actual or potential harm to the child's health, survival, development, or dignity. Child maltreatment is generally perpetrated in the context of a relationship where the perpetrator holds responsibility, trust, or power over the child, such as the parent-child relationship [1]. The estimated prevalence of child maltreatment varies, depending on the country, the definition used, and the assessment methods. A previous review of a series of meta-analyses showed that the overall estimated prevalence rates of self-reported child maltreatment were $22.6 \%$, for physical abuse, and $36.3 \%$, for emotional abuse [9]. In high-income countries, such as the UK and the USA, the prevalence varied from 9 to $12 \%$ [10-12]. Unfortunately, reliable statistics are missing for a large number of countries - including France [13]. Maltreatment by peers (i.e., victimization) during childhood is a multifaceted experience, defined as harm caused by peers acting outside the norms of appropriate conduct [14]. The estimated prevalence of peer victimization varies, depending on the samples, the age of the cohort, and the methodology [15]. According to the World Health Organization, across 38 countries or regions, one in three children reported being bullied (a form of peer victimization involving an imbalance of power between the victim and the perpetrator), but the prevalence declined after the age of 11 years old [2].

Strong evidence from previous studies has suggested that children that experience maltreatment are at a higher risk of being victimized by their peers [14, 16-20]. Moreover, experiencing both forms of interpersonal violence is associated with an increased risk of mental disorders [21], compared to experiencing either maltreatment or peer victimization alone. Given the link between maltreatment and peer victimization and their long-term effects on mental health outcomes, it is relevant to investigate whether peer victimization might be associated with mental health problems, independent from maltreatment. Conversely, failing to take into account maltreatment when investigating associations between victimization and mental health problems could also obscure the potential combined effect of victimization and maltreatment on mental health outcomes [22]. Few previous studies have analyzed the separate and combined effects of peer victimization and maltreatment on mental health problems.

In the present study, our objective was to distinguish between these two types of interpersonal violence during childhood and their effects on mental health problems in young adulthood. Specifically, we tested whether peer victimization alone or in combination with parental maltreatment, experienced before 18 years old, was associated with anxiety, depression, and suicidal thoughts and behaviors (STB) at age 21 years, in a young adult French population.

\section{Methods}

\section{Design, study population, and data collection}

Our study sample comprised participants of the ongoing, Internet-based Students' Health Research Enterprise (iShare) project, a prospective, population-based study of volunteer students in French-speaking universities and higher education institutions. Enrollment in the i-Share project started in 2013; to be eligible, a student had to be officially registered at a University or higher education institute, at least 18 years of age, able to read and understand French, and provide informed consent for participation. The i-Share enrollment procedure was described previously [23].

The self-administered baseline questionnaire collected sociodemographic characteristics, health information, personal and familial histories, living conditions, and consumptions. For this cross-sectional retrospective study, participants completed the baseline questionnaire and a complementary questionnaire, which was proposed after inclusion to the study. Student volunteers received compensation of a 20-euro gift card for completing the supplementary questionnaire, part of which included questions about childhood adversity. For the present study, we retrieved data from a sample of students that were included in the i-Share cohort study between February 2013 and September 2019, had participated in the complementary questionnaire, and had data available on the outcomes of interest. 


\section{Measures}

Outcomes

- Anxiety. Participants completed the Spielberger State-Trait Anxiety Inventory (STAI-Y) [24]. Scores ranged from 20 to 80 points, and higher scores indicated greater anxiety. Cut offs that ranged from 39 to 55 have been suggested for detecting clinically relevant symptoms of anxiety [25, 26]. In our sample of young adults, we set the threshold to the third quartile. Thus, we defined "anxiety" as a binary variable with a STAI-Y score of 54 or higher.

- Depression. Participants completed the 9-item Patient Health Questionnaire (PHQ-9), which is a reliable, valid measure of depression severity over the preceding 2 weeks. Depression severities were graded according to PHQ-9 scores: 5 indicated mild depression, 10 indicated moderate depression, 15 indicated moderately severe depression, and 20 indicated severe depression. The 'depression' outcome was a binary variable, defined as a PHQ-9 score of 15 or higher, which reflected moderate to severe symptoms [27].

- Suicidal thoughts and behaviors. The baseline questionnaire included an STB assessment with single-item questions about suicidal thoughts during the last 12 months and lifetime suicide attempts. Suicidal thoughts were investigated with the question: "In the last 12 months, how often have you thought of attempting suicide (had suicidal ideation)?" Participants selected one of three possible responses: (1) no suicidal thoughts, (2) occasional suicidal thoughts, and (3) frequent suicidal thoughts. Suicide attempts are investigated with the question: "During your lifetime, have you attempted suicide?". The variable "suicidal thoughts and behaviors" was divided into three modalities: "no" for no STBs (reference group); "suicidal thoughts without a suicide attempt" for occasional or frequent suicidal thoughts in the last 12 months, but no lifetime suicidal attempt; and "suicidal thoughts and suicide attempt" for occasional or frequent suicidal thoughts in the last 12 months and at least one lifetime suicide attempt.

- Any mental health problems. Participants with positive scores for depression, anxiety, or STBs were considered to have 'any mental health problem' ('yes'), and these were compared to participants who reported none of these problems ('no').

\section{Exposure}

We assessed maltreatment and/or peer victimization using 17 questions from the Childhood Trauma Questionnaire [28]. Physical and psychological maltreatments were investigated with the following questions, respectively: 1) In your childhood or adolescence, did you feel that you were physically abused (beatings, physical punishment...) by your parents? 2) In your childhood or adolescence, did you ever feel like you had been psychologically or emotionally abused (unfair and frequent criticism, mockery, insults, humiliation, etc.) by your parents? Peer victimization was investigated with the question: In your childhood or adolescence, were you harassed by other children (i.e., regularly insulted or mocked or hit?) For all these questions, the answers "Never" and "Rarely" were coded as "No", and the answers "Sometimes", "Often", and "Very often" were coded as "Yes".

From these data, we defined an exposure variable for maltreatment and/or peer victimization. This variable had four categories: "None" for participants that answered no to all questions; "Peer victimization only" for participants that only answered yes to peer victimization; "Maltreatment only" for participants that only answered yes to maltreatment; and, "Both" for participants that answered yes to both maltreatment and victimization.

\section{Covariates}

We searched the literature to identify potential confounders related to childhood adversities that were associated with both mental health outcomes and the exposure variable. Thus, the following self-reported covariates were considered in the analyses: age, sex (male, female), parental divorce or separation (yes, no), parental depression or anxiety history (yes, no), parental alcohol abuse history (yes, no), parental education level (university studies, non-university studies), and a difficult economic status in childhood (yes, no).

\section{Statistical analyses}

We first described the overall study sample, and grouped participants according to the categories of the exposure variable (i.e., none, peer victimization only, maltreatment only, or both maltreatment and peer victimization). Continuous variable "age" is expressed as the mean \pm standard error. Categorical variables are described as the count and proportion (\%). The Kruskal-Wallis test was used to compare distributions of age in the exposure variable groups. Proportions were compared with the Chi-square test.

We evaluated maltreatment and/or peer victimization associations with other binary outcomes (i.e., "anxiety", "depression", or "any mental health problems") by performing binary logistic regression analyses. The results are expressed as adjusted odds ratios (aORs) with 95\% confidence intervals (CIs). Because STB was a categorical variable with three modalities, we constructed multinomial logistic regression models to assess relationships 


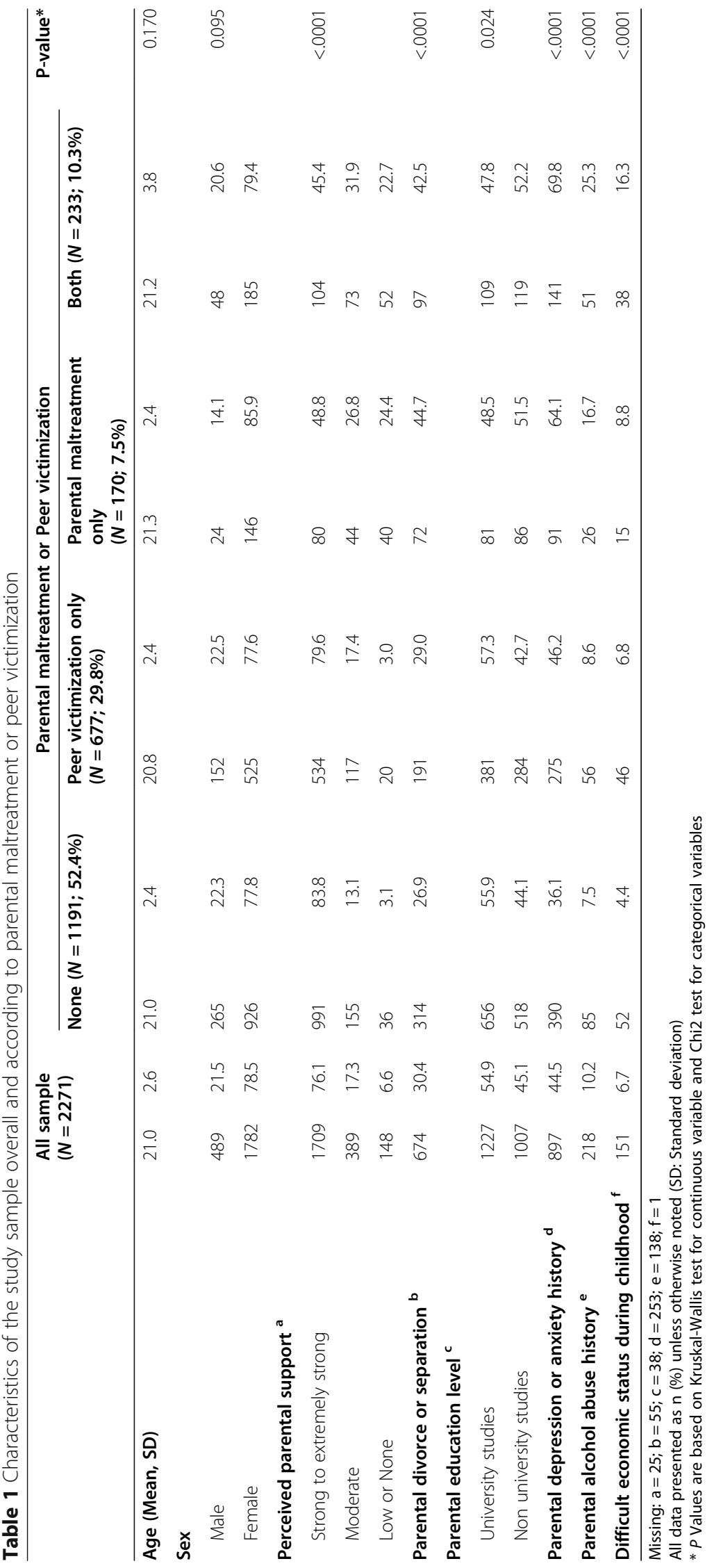


between STBs and exposures. Model convergences were checked. The assumption of linearity of the logit was tested for the continuous variable, age, in each model. The fully adjusted analyses took into account all selected covariates. In each model, to account for missing information on covariates, we used the multiple imputation by chained equation method [29]. Briefly, we performed 10 imputations and averaged the variable estimates to produce a mean estimate. Finally, we verified that the relative efficiency of the imputation for each variable was greater than $95 \%$. We also constructed multivariate models to test the interaction between participant sex and the exposure variable for each outcome. Then, to test the cumulative effect of both maltreatment and victimization on mental health outcomes, compared to peer victimization alone and maltreatment alone, we conducted the same analyses, but changed the reference categories.

Finally, the attributable fraction (AF) was defined as the proportion of each mental health outcome that was attributable to peer victimization or parental maltreatment or both, calculated as follows: $\mathrm{AF}=\left[\mathrm{p}^{*}(\mathrm{aOR}-1)\right] /$ $\left[1+\left(\mathrm{p}^{*}(\mathrm{aOR}-1)\right]\right.$, where $\mathrm{p}$ was the prevalence of the risk factor in our study sample, and aOR was the adjusted odds ratio related to the association between the risk factor and the outcome in the multivariate model after the imputation for missing data.

All analyses were performed with SAS version 9.4. Two-sided $P$ values $<0.05$ were considered statistically significant.

\section{Results}

Of the 2476 students that fully completed the baseline and childhood adversity questionnaires, 205 were excluded, due to missing data for the outcomes. Therefore, the final analysis included 2271 students. The mean age of the participants was 21.0 years $(\mathrm{SD} \pm 2.6)$, and about three quarters were female $(n=1782 ; 78.5 \%)$. Nearly one third of the students reported at least one mental health problem $(n=654 ; 28.8 \%) ; 22.4 \%(n=509)$ reported anxiety, $13.6 \%(n=308)$ reported depression symptoms,
18.3\% $(n=415)$ reported 12-month suicidal ideations, without a lifetime suicide attempt, and 4.0\% $(n=91)$ reported suicidal ideations with a suicide attempt. Mental health problems were more frequent among females than among males, including suicidal thoughts without a suicide attempt ( $18.5 \%$ vs. $17.6 \%)$, suicidal thoughts with a suicide attempt ( $4.2 \%$ vs. $3.5 \%)$, depression $(15.0 \%$ vs. $8.4 \%)$, and anxiety ( $25.1 \%$ vs. $12.5 \%)$. Table 1 shows the characteristics of participants in the overall sample and in the maltreatment and/or peer victimization groups. Nearly one third of the sample $(n=677 ; 29.8 \%)$ was exposed to peer victimization alone; $7.5 \%(n=170)$ was exposed to maltreatment alone; and $10.3 \%(n=233)$ was exposed to both maltreatment and peer victimization. Participants in the two latter groups were more likely to declare negative family events, such as parental divorce, parental depression history, or parental alcohol abuse history, compared to participants in the groups that reported either no adversity or peer victimization alone.

Table 2 shows the adjusted logistic regression model results for associations between maltreatment and/or peer-victimization and mental health outcomes, after multiple imputations for missing data on the covariates. Relative to participants that did not experience any maltreatment or peer victimization, those that experienced peer victimization alone had increased odds of anxiety (aOR: 1.90; 95\% CI: 1.50-2.40), depression (aOR: 1.95; 95\% CI: 1.46-2.60), suicidal ideation without a suicide attempt (aOR: 1.62; 95\% CI: 1.26-2.09), and suicidal ideation with a suicide attempt (aOR: 2.70; 95\% CI: 1.51-4.85). Similar associations were observed for participants that were exposed to maltreatment alone. Participants that experienced both maltreatment and peer victimization were also more likely to present any mental health problems (aOR: 2.94; 95\% CI: 2.17-4.00), depression (aOR: 2.63; 95\% CI: 1.79-3.86), or suicidal thoughts with a suicide attempt (aOR of 9.19; 95\% CI: 4.48-19.92), compared to participants that did not experience either maltreatment or peer victimization.

Additionally, we found an interaction between exposure to interpersonal violence and the participant's sex

Table 2 Associations between mental health outcomes and parental maltreatment and/or peer victimization ( $\mathrm{N}=2271)$

\begin{tabular}{|c|c|c|c|c|c|c|c|c|c|c|}
\hline \multirow[t]{2}{*}{$\begin{array}{l}\text { Maltreatment or } \\
\text { Peer victimization }\end{array}$} & \multicolumn{2}{|c|}{$\begin{array}{l}\text { Suicidal thoughts without } \\
\text { attempt }\end{array}$} & \multicolumn{2}{|c|}{$\begin{array}{l}\text { Suicidal thoughts } \\
\text { with attempt }\end{array}$} & \multicolumn{2}{|c|}{ Depression } & \multicolumn{2}{|c|}{ Anxiety } & \multicolumn{2}{|c|}{$\begin{array}{l}\text { Any mental health } \\
\text { problems }\end{array}$} \\
\hline & $n$ & OR (95\% Cl) & $n$ & OR (95\% CI) & $n$ & OR (95\% Cl) & $n$ & OR (95\% Cl) & $n$ & OR (95\% Cl) \\
\hline None & 162 & 1(reference) & 20 & 1 (reference) & 109 & 1(reference) & 188 & 1(reference) & 246 & 1(reference) \\
\hline Peer victimization only & 140 & $1.62(1.26-2.09)$ & 29 & $2.70(1.51-4.85)$ & 112 & $1.95(1.46-2.60)$ & 183 & $1.90(1.50-2.40)$ & 225 & $1.84(1.48-2.29)$ \\
\hline Maltreatment only & 45 & $2.08(1.41-3.07)$ & 8 & $2.54(1.08-6.00)$ & 31 & $1.85(1.18-2.91)$ & 54 & $2.16(1.49-3.13)$ & 69 & $2.18(1.54-3.09)$ \\
\hline Both & 68 & $2.64(1.86-3.76)$ & 34 & 9.19 (4.98-16.92) & 56 & $2.63(1.79-3.86)$ & 84 & $2.62(1.89-3.64)$ & 114 & $2.94(2.17-4.00)$ \\
\hline
\end{tabular}

OR: odds ratio, $\mathrm{Cl}$ : confidence interval

Adjusted for age, sex, parental divorce or separation, difficult economic status during childhood, parental depression or anxiety history, parental alcohol abuse history and parental education level after multiple imputation 
Table 3 Associations between mental health outcomes and parental maltreatment only or peer victimization only vs both maltreatment and peer victimization

\begin{tabular}{|c|c|c|c|c|c|c|c|c|c|c|}
\hline \multirow[t]{2}{*}{$\begin{array}{l}\text { Maltreatment or Peer } \\
\text { victimization vs Both }\end{array}$} & \multicolumn{2}{|c|}{$\begin{array}{l}\text { Suicidal thoughts } \\
\text { without attempt }\end{array}$} & \multicolumn{2}{|c|}{$\begin{array}{l}\text { Suicidal thoughts } \\
\text { with attempt }\end{array}$} & \multicolumn{2}{|c|}{ Depression } & \multicolumn{2}{|c|}{ Anxiety } & \multicolumn{2}{|c|}{$\begin{array}{l}\text { Any mental health } \\
\text { problems }\end{array}$} \\
\hline & $\mathrm{n}$ & OR $(95 \% \mathrm{Cl})$ & $n$ & OR $(95 \% \mathrm{Cl})$ & $n$ & OR $(95 \% \mathrm{Cl})$ & $\mathrm{n}$ & OR $(95 \% \mathrm{Cl})$ & $\mathrm{n}$ & OR $(95 \% \mathrm{Cl})$ \\
\hline \multicolumn{11}{|l|}{ Model $1(N=910)$} \\
\hline Peer victimization only & 140 & 1 (reference) & 29 & 1 (reference) & 112 & 1 (reference) & 183 & 1 (reference) & 225 & 1 (reference) \\
\hline Both & 68 & $1.64(1.18-2.35)$ & 34 & $3.41(1.95-5.97)$ & 56 & $1.35(0.92-1.98)$ & 84 & $1.38(0.99-1.93)$ & 114 & $1.60(1.17-2.19)$ \\
\hline \multicolumn{11}{|l|}{ Model $2(N=403)$} \\
\hline Maltreatment only & 45 & 1 (reference) & 8 & 1 (reference) & 31 & 1 (reference) & 54 & 1 (reference) & 69 & 1 (reference) \\
\hline Both & 68 & $1.28(0.81-2.03)$ & 34 & $3.65(1.60-8.33)$ & 56 & $1.41(0.86-2.35)$ & 84 & $1.22(0.79-1.87)$ & 114 & $1.35(0.90-2.03)$ \\
\hline
\end{tabular}

OR odds ratio, $\mathrm{Cl}$ : confidence interval

Adjusted for age, sex, parental divorce or separation, difficult economic status during childhood, parental depression or anxiety history, parental alcohol abuse history and parental education level after multiple imputation

$(p<0.0001)$. However, due to the small number of males in some exposure categories, we could not stratify the analyses by sex.

Table 3 shows the mental health outcomes in the group exposed to both maltreatment and peer victimization compared to the groups exposed to either peer victimization or maltreatment alone. The outcomes were not significantly different between participants that experienced maltreatment combined with peer victimization and those that experienced maltreatment alone, except for suicidal thoughts with suicide attempts (aOR: 3.65; 95\% CI: $1.60-8.33)$. Compared to peer victimization alone, the combination of maltreatment and peer victimization showed significantly stronger associations with any mental health problems (aOR: 1.60; 95\% CI: 1.17-2.19) and suicidal thoughts, with or without suicide attempts. In contrast, these two exposure groups showed similar associations with depression and anxiety.

The AFs ranged from 6.0 to $45.8 \%$ (Table 4) in our study sample. We observed that, for the outcome of any mental health disorders, the AF for peer victimization alone was larger than the AF for maltreatment alone. The AFs for peer victimization alone were closer to the AFs for combined maltreatment and victimization than to the AFs for maltreatment alone. For example, 20.0\% of any mental health disorder and $15.6 \%$ of suicidal ideation without a suicide attempt could be attributed to peer victimization. In comparison, the corresponding AFs for maltreatment combined with peer victimization were $16.7 \%$ and $14.5 \%$, respectively, and the AFs for maltreatment alone were $8.1 \%$ and $7.5 \%$, respectively.

\section{Discussion}

\section{Main findings and interpretation}

In this cross-sectional study of 2271 young French adults, we found an increased risk of mental health problems, including anxiety, depression, and STBs, in individuals that had been victimized by peers, whether or not they were exposed to parental maltreatment in childhood. Among individuals that were exposed to both maltreatment and peer victimization during childhood, depression and anxiety did not occur significantly more frequently than those exposed to either maltreatment or peer victimization alone. However, the combined exposure significantly increased the risk of suicidal thoughts with suicide attempts, compared to either exposure alone.

The prevalence of peer victimization and maltreatment in our sample were close to those estimated in previous studies [2, 10-12]. Peer victimization alone was highly prevalent (one third of the sample), which explained the large AFs, comparable to the AFs of the combination of maltreatment and peer victimization.

Our results suggested that peer victimization played an important, independent role in mental health problems, consistent with findings in other studies [30]. A previous longitudinal study highlighted the finding that peer victimization had an independent effect on the mental health of young adults, and the long-term

Table 4 Attributable fractions (\%) of parental maltreatment and/or peer victimization for mental health outcomes

\begin{tabular}{|c|c|c|c|c|c|}
\hline & $\begin{array}{l}\text { Suicidal thoughts } \\
\text { without attempt }\end{array}$ & $\begin{array}{l}\text { Suicidal thoughts } \\
\text { with attempt }\end{array}$ & Depression & Anxiety & $\begin{array}{l}\text { Any mental } \\
\text { health problems }\end{array}$ \\
\hline Peer victimization only & 15.6 & 33.6 & 22.0 & 21.1 & 20.0 \\
\hline Maltreatment only & 7.5 & 10.4 & 6.0 & 8.0 & 8.1 \\
\hline Both & 14.5 & 45.8 & 14.4 & 14.3 & 16.7 \\
\hline
\end{tabular}


adverse effects on mental health were worse than the effects from maltreatment [31]. Previous studies also showed that peer victimization had an important effect on mental health problems; indeed, the risk of negative mental health outcomes was similar between children that had experienced bullying victimization and children that were placed in institutional or foster care [32].

Studies have shown that parental support and a positive familial relationship in childhood have positive longterm effects on adult mental health and provide a crucial foundation for social interactions [33, 34]. Thus, parental maltreatment in childhood increases the likelihood that a child will be victimized by peers, due to the child's impaired emotional regulation skills [35]. Indeed, attachment theory highlights the fact children internalize aspects of caregiving relationships, and this experience can later impair peer interactions [36]. It is worth noting that maltreatment and peer victimization refer to experiences of interpersonal violence that occurs in two different environmental contexts - the home and the school, respectively. It is possible that some individuals that experience maltreatment in the home environment see themselves as victims, regardless of the context. However, our results showed that associations between peer victimization and mental health outcomes were not fully explained by exposure to both these types of interpersonal violence. Moreover, these associations remained significant, even after controlling for important familial variables. This finding emphasized the importance of interpersonal experiences that occur outside the family sphere, and specifically with peers, which appear to play a specific role in mental health. As children grow-up, peer interactions become increasingly important. Repetitive verbal or physical harassment or exclusion from peers might have long-term effects, independent of other childhood adversities, and thus, they can modify responses to stress [37]. Furthermore, our findings suggested that cumulative maltreatment effects may be at least partly due to victimization. Thus, future studies of maltreatment should also take into account peer victimization.

In suicide ideation-to-action frameworks, such as the Interpersonal Psychological Theory of Suicide [38], or more recently, the Three-Step Theory [39], the development of suicide ideation and its progression to suicide attempts are distinct processes with different explanations and risk factors. These theories emphasize an 'acquired capability', which refers to an individual's habituation to pain or fear through exposure to life experiences, such as abuse or other painful events. Our findings showed that cumulative exposures to parental maltreatment and peer victimization were more strongly associated with the risk of suicidal ideation and suicide attempts than with the risk of suicide ideation alone.
This finding suggested that cumulative experiences could promote progression of the acquired capability from suicide ideation to suicide attempts.

\section{Strengths and limitations}

The present study had some important strengths, including the large, contemporaneous sample of young French adults, a study population never investigated on this subject. We also note the consistency of our results with previous studies, and the ability to adjust for a range of confounders, due to the data available on a wide range of variables. Depression and anxiety were measured with validated scales that had excellent psychometric properties. Furthermore, we found a significant association between peer victimization alone and each mental health outcome, which provided consistent results. Despite these strengths, several limitations should be considered when interpreting the results. First, the study design was cross-sectional; therefore, we could not strictly correlate the exposure timing to the outcome and the covariates, and we could not infer causality between the exposure and the mental health outcomes. Second, the voluntary participation of students in the baseline and supplementary questionnaires may have introduced a self-selection bias, although it is difficult to predict how this potential bias could have influenced the results. Third, the information was self-reported, which could lead to an information bias, particularly a memory bias, because the exposure assessment was retrospective. Fourth, there was an over-representation of women in our sample, compared to the $56 \%$ of female students in France, and our results suggested that there were differences between the sexes, in terms of mental health problems and maltreatment exposure. Fifth, we did not analyze physical and psychological maltreatments separately, with regard to peer victimization. Finally, we could not investigate the age of onset for peer victimization and/or maltreatment.

\section{Conclusions}

This study showed that, in a large sample of young adults, exposures to parental maltreatment and/or peer victimization in childhood or adolescence were associated with an increased risk of mental health problems. Peer victimization appeared to play a specific role in mental health problems, beyond the role of exposure to maltreatment. Peer victimization occurs frequently, but it is preventable. Therefore, our findings stress the importance of coordinating the efforts of schools, teachers, health services, and public policies in addressing this widespread problem.

\section{Abbreviations}

AF: Attributable fraction; aOR: Adjusted odds ratio; Cl: Confidence interval; iShare: Internet-based Students' Health Research Enterprise; OR: Odds ratio; 
PHQ-9: Patient Health Questionnaire; SD: Standard deviation; STAI: State-Trait Anxiety Inventory; STB: Suicidal thoughts and behaviors

\section{Acknowledgements}

The authors would like to thank the coordinating team of the i-Share project for their assistance in setting up and collecting data. In particular, we would like to thank: Clothilde Pollet, Edwige Pereira, Marie Mougin, Elena Milesi, Aude Pouymayou, and Garance Perret. We thank all the students that participated in the i-Share study.

\section{Authors' contributions}

$M M, C T$, and SMC designed the study. MM conducted the statistical analysis. MM, MO, CT and SMC wrote the first draft of the manuscript. All co-authors had full access to the data and read, revised, and approved the final manuscript.

\section{Funding}

The preparation and initiation of the i-Share project was funded by the program, 'Invest for the future' (reference ANR-10-COHO-05). The i-Share team was supported by an unrestricted grant from the Nouvelle-Aquitaine Regional Council (Conseil Régional Nouvelle-Aquitaine) (grant $N^{\circ}$ 4370420). The i-Share team also received grants from the Nouvelle-Aquitaine Regional Health Agency (Agence Régionale de Santé Nouvelle-Aquitaine), Public Health France (Santé Publique France) (contract N 19DPPP023-0) and The National Institute against cancer INCa (grant INCa_11502). M. Macalli was supported by PhD grants from the Nouvelle-Aquitaine Regional Counci (grant N 17 EURE-0019) and the PhD Digital Public Health Graduate School Program, supported within the framework of the PIA3 (Investment for the Future) (project reference: 18-EURE-0019). The funding sponsor played no role in the design of the study; in the collection, analyses, or interpretation of data; in writing the manuscript; or in the decision to publish the results.

\section{Availability of data and materials}

The datasets used and/or analyzed during the current study are available from the corresponding author on reasonable request.

\section{Declarations}

\section{Ethics approval and consent to participate}

The i-Share project was approved by the "Commission nationale de l'informatique et des libertés" (National Commission of Informatics and Liberties, Reference DR-2013-019). All methods were carried out in accordance with relevant guidelines and regulations. Students were informed of the nature and purpose of the study, and all participants provided informed consent online.

\section{Consent for publication}

Not applicable.

\section{Competing interests}

The authors declare no competing interests.

\section{Author details}

'University of Bordeaux, Inserm, Bordeaux Population Health Research Center, UMR 1219, F-33000 Bordeaux, France. ${ }^{2}$ McGill Group for Suicide Studies, Douglas Mental Health University Institute and Department of Psychiatry, McGill University, Montreal, QC, Canada. ${ }^{3} \mathrm{CHU}$ de Bordeaux, F-33000 Bordeaux, France. ${ }^{4}$ School of Public Health, University of Montreal, Montreal, QC H3T 1J4, Canada.

\section{Received: 16 February 2021 Accepted: 28 May 2021}

Published online: 14 July 2021

\section{References}

1. World Health Organization WHO. Child maltreatment. https://www.who.int/ news-room/fact-sheets/detail/child-maltreatment (2020). Accessed 9 Dec 2020

2. World Health Organization WHO. Social determinants of health and wellbeing among young people. Health Behaviour in School-aged Children (HBSC) study: international report from the 2009/2010 survey. https://www. euro.who.int/en/publications/abstracts/social-determinants-of-health-and- well-being-among-young-people.-health-behaviour-in-school-aged-childrenhbsc-study (2012). Accessed 9 Dec 2020.

3. Angelakis I, Austin $J$, Gooding P. Association of childhood maltreatment with suicide behaviors among young people: a systematic review and meta-analysis. JAMA Netw Open. 2020;3(8):e2012563. https://doi.org/10.1 001/jamanetworkopen.2020.12563.

4. Norman RE, Byambaa M, De R, Butchart A, Scott J, Vos T. The long-term health consequences of child physical abuse, emotional abuse, and neglect: a systematic review and meta-analysis. PLoS Med. 2012;9(11):e1001349. https://doi.org/10.1371/journal.pmed.1001349.

5. Stapinski LA, Bowes L, Wolke D, Pearson RM, Mahedy L, Button KS, et al. Peer victimization during adolescence and risk for anxiety disorders in adulthood: a prospective cohort study. Depress Anxiety. 2014;31(7):574-82 https://doi.org/10.1002/da.22270

6. Sourander A, Jensen $P$, Rönning JA, et al. What is the early adulthood outcome of boys who bully or are bullied in childhood? The Finnish "from a boy to a man" study. Pediatrics. 2007;120(2):397-404. https://doi.org/10.1 542/peds.2006-2704

7. Klomek AB, Sourander A, Niemelä S, Kumpulainen K, Piha J, Tamminen T, et al. Childhood bullying behaviors as a risk for suicide attempts and completed suicides: a population-based birth cohort study. J Am Acad Child Adolesc Psychiatry. 2009 Mar;48(3):254-61. https://doi.org/10.1097/CHI. Ob013e318196b91f.

8. Holt MK, Vivolo-Kantor AM, Polanin JR, Holland KM, DeGue S, Matjasko JL, et al. Bullying and suicidal ideation and behaviors: a meta-analysis. Pediatrics. 2015;135(2):e496-509. https://doi.org/10.1542/peds.2014-1864.

9. Stoltenborgh $M$, Bakermans-Kranenburg M J, Alink RA, Van-ljzendoorn MH The prevalence of child maltreatment across the globe: Review of a series of meta-analyses. Child Abuse Review. 2015; doi. org/https://doi.org/10.1 002/car.2353.

10. Gilbert R, Widom CS, Browne K, Fergusson D, Webb E, Janson S. Burden and consequences of child maltreatment in high-income countries. Lancet. 2009;373(9657):68-81. https://doi.org/10.1016/S0140-6736(08)61706-7.

11. Wildeman C, Emanuel N, Leventhal JM, Putnam-Hornstein E, Waldfogel J, Lee $\mathrm{H}$. The prevalence of confirmed maltreatment among US children, 2004 to 2011. JAMA Pediatr. 2014;168(8):706-13. https://doi.org/10.1001/jama pediatrics.2014.410.

12. Radford L, Corral S, Bradley C, et al. Child abuse and neglect in the UK today. London: National Society for the Prevention to Cruelty to Children, 2011.

13. Tursz A. La maltraitance des enfants en France - Prendre enfin la mesure de son poids individuel et sociétal [Child abuse and neglect in France. Finally recognize its individual and societal impact]. Med Sci (Paris). y; French. doi: https://doi.org/10.1051/medsci/20173310001.

14. Oncioiu SI, Orri M, Boivin M, Geoffroy MC, Arseneault L, Brendgen M, et al. Early childhood factors associated with peer victimization trajectories from 6 to 17 years of age. Pediatrics. 2020;145(5):e20192654. https://doi.org/10.1 542/peds.2019-2654.

15. Husky MM, Delbasty E, Bitfoi A, Carta MG, Goelitz D, Koç C, et al. Bullying involvement and self-reported mental health in elementary school children across Europe. Child Abuse Negl. 2020;107:104601. https://doi.org/10.1016/j. chiabu.2020.104601.

16. Lereya ST, Samara M, Wolke D. Parenting behavior and the risk of becoming a victim and a bully/victim: a meta-analysis study. Child Abuse Negl. 2013; 37(12):1091-108. https://doi.org/10.1016/j.chiabu.2013.03.001.

17. Radford L, Corral S, Bradley C, Fisher HL. The prevalence and impact of child maltreatment and other types of victimization in the UK: findings from a population survey of caregivers, children and young people and young adults. Child Abuse Negl. 2013;37(10):801-13. https://doi.org/10.1016/j.chia bu.2013.02.004

18. Ssenyonga J, Magoba Muwonge C, Hecker T. Prevalence of family violence and mental health and their relation to peer victimization: a representative study of adolescent students in southwestern Uganda. Child Abuse Negl. 2019;98:104194. https://doi.org/10.1016/j.chiabu.2019.104194.

19. Turner HA, Finkelhor D, Ormrod R. Poly-victimization in a national sample of children and youth. Am J Prev Med. 2010;38(3):323-30. https://doi.org/10.1 016/j.amepre.2009.11.012.

20. Wang Q. Association of childhood intrafamilial aggression and childhood peer bullying with adult depressive symptoms in China. JAMA Netw Open. 2020;3(8):e2012557. https://doi.org/10.1001/jamanetworkopen.2020.12557.

21. Holt MK, Finkelhor D, Kantor GK. Multiple victimization experiences of urban elementary school students: associations with psychosocial functioning and 
academic performance. Child Abuse Negl. 2007;31(5):503-15. https://doi. org/10.1016/j.chiabu.2006.12.006.

22. Finkelhor D, Ormrod RK, Turner HA. Poly-victimization: a neglected component in child victimization. Child Abuse Negl. 2007;31(1):7-26. https://doi.org/10.1016/j.chiabu.2006.06.008.

23. Macalli M, Tournier M, Galéra C, Montagni I, Soumare A, Côté SM, et al. Perceived parental support in childhood and adolescence and suicidal ideation in young adults: a cross-sectional analysis of the i-share study. BMC Psychiatry. 2018;18(1):373. https://doi.org/10.1186/s12888-018-1957-7.

24. Laux L, Glanzmann P, Schaffner P, Spielberger C. Das state-trait Angstinventar: STAl. Beltz Test GmbH: Weinheim; 1981.

25. Wiglusz MS, Landowski J, Cubała WJ. Psychometric properties and diagnostic utility of the state-trait anxiety inventory in epilepsy with and without comorbid anxiety disorder. Epilepsy Behav. 2019;92:221-5. https:// doi.org/10.1016/j.yebeh.2019.01.005

26. Julian LJ. Measures of anxiety: state-trait anxiety inventory (STAI), Beck anxiety inventory (BAI), and hospital anxiety and depression scale-anxiety (HADS-A). Arthritis Care Res (Hoboken). 2011;63(S11):S467-72. https://doi. org/10.1002/acr.20561.

27. Kroenke K, Spitzer RL, Williams JB. The PHQ-9: validity of a brief depression severity measure. J Gen Intern Med. 2001;16(9):606-13. https://doi.org/10.1 046/j.1525-1497.2001.016009606.x.

28. Paquette D, Laporte L, Bigras M, Zoccolillo M. Validation of the french version of the CTQ and prevalence of the history of maltreatment. Sante Ment Que. 2004;29(1):201-20. https://doi.org/10.7202/008831ar.

29. Van Buuren S. Multiple imputation of discrete and continuous data by fully conditional specification. Stat Methods Med Res. 2007;16(3):219-42. https:// doi.org/10.1177/0962280206074463.

30. Copeland WE, Wolke D, Angold A, Costello EJ. Adult psychiatric outcomes of bullying and being bullied by peers in childhood and adolescence. JAMA Psychiatry. 2013;70(4):419-26. https://doi.org/10.1001/jamapsychiatry.2013.504.

31. Lereya ST, Copeland WE, Costello EJ, Wolke D. Adult mental health consequences of peer bullying and maltreatment in childhood: two cohorts in two countries. Lancet Psychiatry. 2015;2(6):524-31. https://doi.org/10.101 6/S2215-0366(15)00165-0.

32. Takizawa R, Maughan B, Arseneault L. Adult health outcomes of childhood bullying victimization: evidence from a five-decade longitudinal British birth cohort. Am J Psychiatry. 2014;171(7):777-84. https://doi.org/10.1176/appi.a jp.2014.13101401.

33. Macalli M, Côté S, Tzourio C. Perceived parental support in childhood and adolescence as a tool for mental health screening in students: a longitudinal study in the i-share cohort. J Affect Disord. 2020;266:512-9. https://doi.org/10.1016/j.jad.2020.02.009.

34. Cowan PA, Cowan CP, Cohn DA, Pearson JL. Parents' attachment histories and children's externalizing and internalizing behaviors: exploring family systems models of linkage. J Consult Clin Psychol. 1996;64(1):53-63. https:// doi.org/10.1037//0022-006x.64.1.53.

35. Shields A, Cicchetti D. Parental maltreatment and emotion dysregulation as risk factors for bullying and victimization in middle childhood. J Clin Child Psychol. 2001;30(3):349-63. https://doi.org/10.1207/S15374424JCCP3003_7.

36. Zeanah $\mathrm{CH}$, Zeanah PD. Intergenerational transmission of maltreatment: insights from attachment theory and research. Psychiatry. 1989;52(2):177-96. https://doi.org/10.1080/00332747.1989.11024442.

37. Copeland WE, Wolke D, Lereya ST, Shanahan L, Worthman C, Costello EJ. Childhood bullying involvement predicts low-grade systemic inflammation into adulthood. Proc Natl Acad Sci U S A. 2014;111(21):7570-5. https://doi. org/10.1073/pnas.1323641111.

38. Van Orden KA, Witte TK, Cukrowicz KC, Braithwaite SR, Selby EA, Joiner TE. The interpersonal theory of suicide. Psychol. Rev. 2019; doi.org/10.1037/a0018697.

39. Klonsky ED, May AM. The three-step theory (3ST): a new theory of suicide rooted in the "ideation-to-action" framework. Int J Cogn Ther. 2015;8(2):11429. https://doi.org/10.1521/ijct.2015.8.2.114.

\section{Publisher's Note}

Springer Nature remains neutral with regard to jurisdictional claims in published maps and institutional affiliations.

\section{Ready to submit your research? Choose BMC and benefit from:}

- fast, convenient online submission

- thorough peer review by experienced researchers in your field

- rapid publication on acceptance

- support for research data, including large and complex data types

- gold Open Access which fosters wider collaboration and increased citations

- maximum visibility for your research: over $100 \mathrm{M}$ website views per year

At BMC, research is always in progress.

Learn more biomedcentral.com/submissions 